THURSDAY, JUNE 27,1872

\section{THE TIDES AND THE TREASURY}

$\mathrm{O}^{\mathrm{U}}$

UR readers may have heard that England is a "sea. girt isle," and that we are a maritime nation, possessing a very powerful navy and an extensive commerce. They also know that the ocean to which we owe these peculiarities is a very restless fluid, its surface being ruffled by the wind, and its entire mass uplifted and depressed from time to time, in what we call tides, by the attractive power of the sun and moon. They know, too, that the theory of the tides has been investigated by the most profound mathematicians, particularly by Laplace, Lubbock, Airy, and Wheweil. And they are, no doubt, aware that the theoretical laws deduced by these learned men, though indispensable as a foundation of our knowledge, are entirely insufficient, by themselves, for the wants of man, the conformation of the coast-line and of the sea bottom powerfully modifying tidal facts. Hence it becomes necessary to resort to observations and surveys in order to know what will be the course of the tides as to heights and times in particular localities frequented by ships, such as roadsteads, harbours, and the mouths of rivers. All this, perhaps, every one of our readers knows ; but it may not, perhaps, be so generally known that the study of the tides throws light on various high cosmical, gravitational, and physico-geographical problems.

The importance of this study is unquestionable, and, indeed, unquestioned; and it has been pursued to a limited extent by ourselves and all civilised nations at the public cost. But as yet the observations have been insufficient both as to character and as to the number of localities at which they have been taken, and also as to the reduction of them, and the deductions from them, that have been made.

Sir William Thomson accordingly brought the subject before the British Association, and obtained from that body the aid of a Committee and of small sums of money from year to year, to enable him to supply, so far as might be possible, these deficiencies. The Committee was designated "for the purpose of promoting the extension, improvement, and harmonic analysis of tidal observations;" and, having regard to the object with which we now address the scientific public, we must also give its composition, namely, Sir W. Thomson, Prof. J. C. Adams, the Astronomer Royal, Mr. J. F. Bateman, C.E., Admiral Sir E. Belcher, Mr. T. G. Bunt, Staff-Commander Burwood, R.N., Mr. Warren De La Rue, Prof. Fischer, Mr. J. P. Gassiot, Prof. Haughton, Mr. J. R. Hind, Prof. Kelland, Staff-Captain Moriarty, Mr. J. Oldham, C.E., Mr. W. Parikes, C.E., Prof. Bartholomew Price, Prof. Rev. C. Pritchard, Prof. Rankine, Captain Richards, Hydrographer to the Navy, Dr. Robinson, Sir E. Sabine, Mr. W. Sissons, Prof. Stokes, General Strachey, Mr. T. Webster, Profs. Fuller and Iselin (secretaries), and Sir W. Thomson (reporter). Every gentleman here named is favourably known, and the majority are highly distinguished, in those branches of the sciences with which the tides are connected.

VOL. VI.
The Committee has made three reports, namely, in I868, 1870, and 1871 , the two first prepared by Sir W. Thomson, and the third by Mr. E. Roberts of the Nautical Alliance Office, under whose able superintendence the computations and deductions were placed. The three reports have been published in extenso by the British Association in the volumes of the above-mentioned years. They bring fully under view the theoretical basis of the investigation, an account of observations made by the Committee and by the authorities, some of the conclusions deduced therefrom, and a statement of the measures recommended in order to extend and perfect our knowledge of the subject. It is impossible to exaggerate the value of these documents. They clearly define the present position of the problem, and the course which any future researches must take.

At the meeting of the Council of the Association on on November II, 1871, the following resolutions were passed :-

(I.) That it is desirable that the British Association apply to the Treasury for funds to enable the Tidal Committee to continue their calculations and observations.

(2.) That it is desirable that the British Association should urge upon the Government of India the importance for navigation and other practical purposes and for science, of making accurate and continued observations on the tides at several points on the Coast of India.

The second of these resolutions has already been prodictive of fruit. Colonel Walker, R.E., the distinguished superintendent of the Great Trigonometrical Survey of India, has, under the authority of the Indian Government, established self-registering tide-gauges at several points in India, and has made adequate arrangements for the reduction of the results.

It is with Resolution ( 1 ) that we are concerned to-day, the official correspondence relating to it having been placed at our disposal for review. This consists of only two documents-a Memorial of the British Association to the Lords of the Treasury, signed by the President, and dated May 21, 1872; and the reply thereto.

The main points dwelt on in the memorial may be thus summarised :-That the primary object which the Committee have uniformly kept in view is " the practical application of their results to Physical Geography, Meteorology, Coast and Harbour Engineering, and Navigation "" that they have undertaken the reduction of twenty years' observations made with self-registering tide-gauges--"a most laborious work;" that $600 l$. has been granted by the British Association in four successive annual sums of $100 \%$. and one of $200 l$., "to pay the calculators, and to print and prepare tables, forms for calculations, \&c. ; that the last grant barely sufficed for the work actually in hand;" and that they now apply to the Government for the sum of 150l., "to secure the continuance of the investigation."

The reply to this memorial is such that, unless printed in extenso, many persons would, we feel certain, refuse to believe that such a document could have been issued with the sanction of a civilised Government. We therefore now append it:- 
"Treasury Chambers, June 3, 1872

"Sir,-.The Chancellor of the Exchequer has referred to the Lords Commissioners of Her Majesty's Treasury the memorial of the British Association for the Advancement of Science, forwarded to him with your letter of the 2 Ist ult., praying for Government assistance in connection with tidal observations.

"I am to state that their Lordships have given their anxious attention to the memorial, and that they are fully sensible of the interesting nature of such investigations; but that they feel that if they acceded to this request it would be impossible to refuse to contribute towards the numerous other objects which men of eminence may desire to treat scientifically.

"Their Lordships must, therefore, though with regret, decline to make a promise of assistance towards the present object out of public funds.

"I am, Sir, your obedient servant, "(Signed) William LAW

"Sir W. Thomson, Athenæum Club."

Nothing would be easier than to be sarcastically indignant on such a theme as this. The picture of the Lords Commissioners of H.M. Treasury giving their "anxious attention" to the tides, and expressing "regret" that they cannot grant so large a sum as $150 l$. for investigations which they really think "interesting," lest eminent men should avail themselves of so imprudent a precedent, in order to make further demands for "scientifically" treating other objects of the same character-this picture is one which requires but a touch, it hardly, indeed, needs a touch, to make it a far-fetched caricature of civilised governing.

To apply the lash, however, to narrow stupidity, can only gratify temporary spleen; and we must resist the temptation in order to attain the higher object of illustrating, by this pointed example, the present condition of State science in Englánd, and of showing what we require in order to prevent the mischief which its existing condition must cause.

To begin with the British Association. Here is a body carrying on operations by means of privately contributed funds, of very limited amount, about 2,000l. a year; not for the first, tenth, or hundredth time, quietly accepting as a fact that certain scientific objects of national importance will not be recognised or pursued by the Government, and, therefore, stepping in to contribute as far as they can towards their accomplishment. The Kew Observatory, the map of the moon, the utilisation of sewage, are other examples of the same kind. They have all been commenced on a necessarily miserable scale-a little advance has been made, and then the thing has dropped through for want of funds. Now, according to our apprehension the British Association, though acting with the very best intentions and motives, have greatly erred in these matters. It is absurd to suppose that any one of the numerous large national scientific problems they have taken up could be properly dealt with even if their whole income of $2,000 l$. a year had been devoted exclusively to it. The small contributions to each which they have been able to afford, if not sometimes quite wasted, have almost invariably produced results quite inadequate even to the small expenditure, simply because it was so small as to forbid really efficient measures. This is an evil, but as some good results, however slight and imperfect, have been achieved, it might be submitted to if it were all. A far greater evil, however, has been caused by the measures we allude to.
An obscurity has been thrown round the great question which England must soon solve. "What is the scrientific work which the Government is bound to perform for the benefit of the community at large ; and what is the scientific work which cannot be performed by State agency so well as by private enterprise?"

So long as individuals, and bodies of individuals, without discrimination, attempt to do what should properly devolve on the State, so long will a Government, destitute, like ours, of a particle of the scientific element, neglect its legitimate duties. We therefore strongly counsel the British Association, at their next meeting, to take measures for classifying science under the two great heads of Public and Private, to supply the Government with a full statement of all comprehended under the first head, and to refuse a single penny of its funds to any object not distinctly appertaining to the second. This will bring matters to a crisis-and we want a crisis.

As to the Government, what can we say? Poor $\mathrm{Mr}$. Law's letter speaks volumes. It plaintively confesses its total inability to grasp any State scientific problem lest it should have to deal with all. We have no heart to spurn a prostrate form so lowly and humble; but can we not raise it? Can we not introduce into our Administration a source of knowledge on which they can rely to guide them in the choice of scientific objects really profitable to the nation, and officials able to insure a proper system for the attainment of such objects?

Many minds are busy on this very question; and the fact that a maritime Government will not give $150 l$. towards investigating the tides is not likely to weaken their determination to bring it to a decisive issue.

\section{PUBLIC HEALTH IN AMERICA}

\section{Third Annual Report of the State Board of Health of} Massachusetts. (Jan. 1872.)

DUBLIC health problems in New England are very 1 much of the same character as they are in old England. The countries and climates are both healthy, and there is plenty of preventible disease notwithstanding. In both countries bad habits have much to do with the causation of disease. In both countries civilisation takes but small account of natural laws, and as a consequence makes one step forwards where two might be made. One reason of this is partly want of knowledge, but the report before us shows that another not unimportant cause is attempting to gain present advantages by discounting the future. It is an old story told in a new country. There is a small present profit to a small minority of the community, at the cost of the remainder; but Nature, as has been well said, "just goes on levying her own cess in her own way," i.e., she sends in her account, not only to the perpetrators of the damage, but to the whole community which tacitly submits to it.

The Report consists of two portions, one part giving a brief account of the Board's proceedings, the other containing an intercsting series of reports by different writers on the effects of arsenical colours on health, on mill dams and water obstructions as causes of disease, on the use and abuse of intoxicating drinks, with reference to a cosmic law of intemperance, on provision for the insane, 